\title{
The use of proton pump inhibitors in treating and preventing NSAID-induced mucosal damage
}

James M Scheiman*

\begin{abstract}
NSAIDs are prescribed widely but have rare serious gastrointestinal side effects. More recently, adverse cardiovascular effects of these drugs have also been recognized, leading to the withdrawal of some agents and continuing uncertainty about the best approach for patients requiring NSAID therapy. Proton pump inhibitors (PPIs) provide potent and long-lasting inhibition of gastric acid secretion and have proven efficacy in healing NSAID-associated ulcers, including those with continued exposure to NSAIDs. PPIs have also shown efficacy in reducing the risk of ulcerations due to NSAID use compared with NSAIDs alone in randomized controlled trials (RCTs) where endoscopic ulcers are used as the primary endpoint, albeit a surrogate marker for clinical ulcers and complications. Large RCT outcome trials comparing patients exposed to NSAIDs with and without PPI co-therapy have not been performed, but adequately powered RCTs in high-risk patients demonstrate that PPI + nonselective NSAID provides similar rates of symptomatic ulcer recurrence rates as the use of a cyclooxygenase (COX)2 selective inhibitor. A RCT in high-risk patients with previous ulcer complications supports the additive benefit of two risk-reducing strategies, as ulcer complication recurrence was eliminated in high-risk patients who were given a COX-2 selective agent with a PPI. Helicobacter pylori, an independent risk factor for ulcers, should be sought out and eradicated in patients at increased gastrointestinal risk, typically those with an ulcer history. Following H. pylori eradication, however, patients remain at risk and co-therapy with a PPI is recommended. NSAID medication selection should consider both the individual patients' gastrointestinal and cardiovascular risks.
\end{abstract}

*Correspondence: jscheima@umich.edu

3912 Taubman Center SPC 5362, University of Michigan, Ann Arbor, MI 481095362, USA

\section{Introduction}

Other articles in this supplement have reviewed the benefits of NSAID therapy. Their efficacy leads to a vast exposure of these medications in diverse patient populations. Damage to the upper gastrointestinal (GI) tract was the first of several potentially serious NSAID adverse events to be identified [1], and still remains a predominant concern. Cardiovascular and related renal toxicity, however, has further complicated strategies to reduce the overall risk of this class of drugs. The recognition of GI toxicity drove pharmaceutical research in two parallel directions in pursuit of effective anti-inflammatory therapy with reduced ulceration and bleeding.

The GI damage caused by NSAIDs can be ameliorated in a number of ways - most effectively by stopping the drug (often an impractical solution), by selecting a less toxic NSAID or by adding a second drug, either prophylactically or following a complication [2]. The introduction of the cyclooxygenase (COX)-2 selective NSAIDs in the late 1990s promised a revolution in NSAID therapy due to sparing of the COX-1 pathway, providing effective control of inflammation and leading to fewer ulcers and bleeding complications. These drugs were widely prescribed until evidence of cardiovascular side effects, including an increased risk of myocardial infarction, gradually began to emerge, and some of the COX-2 NSAIDs were eventually withdrawn from general use in Europe and North America [3].

Concomitant innovations in pharmacotherapy for ulcer disease, particularly the development of potent acid suppression with proton pump inhibitors (PPIs), as well as recognition of the role of Helicobacter pylori, expanded research dramatically in ulcer-reducing approaches. Cotherapy options with NSAIDs currently include $\mathrm{H}_{2}-$ receptor antagonists (H2RAs), PPIs, and prostaglandin analogs, each of which possess varying efficacy as a gastroprotective agent and some of which cause further problems with their own side effects.

Other articles in this supplement have comprehensively reviewed the epidemiology of NSAID-related ulcers as well as the mechanisms underlying the initiation and perpetuation of injury. NSAIDs inhibit prostaglandin production in the upper GI tract mucosa, and since 
defense and repair is prostaglandin dependent, the stomach and duodenum are rendered vulnerable in the face of continuous acid production. This pathophysiology provides the scientific rationale for gastroprotection options to include supplementation with synthetic prostaglandin analogs, agents that induce gastric acid suppression, or the selective use of those NSAIDs least likely to inhibit upper GI prostaglandin synthesis, such as COX-2 selective inhibitors [4].

A prostaglandin analog not further discussed in this supplement, full-dose misoprostol $800 \mu \mathrm{g} /$ day has been demonstrated superior to $400 \mu \mathrm{g} /$ day for the prevention of endoscopic gastric ulcers (relative risk $(R R)=0.17$, and $\mathrm{RR}=0.39$ respectively; $P=0.0055)$. A dose-response relationship was not seen with duodenal ulcers. Misoprostol caused diarrhea at all doses, although significantly more at $800 \mu \mathrm{g} /$ day than at $400 \mu \mathrm{g} /$ day $(P=0.0012)$. Misoprostol has also been shown to reduce clinically serious adverse outcomes in a larger outcome study [5]. The frequency of side effects severe enough to cause discontinuation of therapy, however, is such that the utility of misoprostol as a gastroprotective agent is limited. Current use of misoprostol remains in lower doses in a single-tablet combination product with diclofenac.

\section{Treatment of NSAID-associated ulcers}

Understanding the evolution in research that provided the basis of PPI therapy for NSAID users began with comparative studies with the well-established, but less potent, acid-suppressive agents that predated PPI use. Intragastric acidity has been shown to be a key predictor of injury to the acid-exposed foregut. Unlike H2RAs, which block a single stimulant of parietal cell acid production, PPIs inhibit the parietal cell proton pump, thus exerting a suppressive effect on gastric acid that is more potent, longer lasting and free of tachyphylaxis [6].

H2RAs heal almost all NSAID ulcers when the patient stops NSAID use. The rate of ulcer healing with H2RA therapy decreases significantly, however, if the patient cannot discontinue NSAIDs. Among 190 NSAID-using patients with endoscopically confirmed ulcers, the H2RA ranitidine $150 \mathrm{mg}$ was given twice daily, and patients were randomized to continue or discontinue NSAID ingestion. Gastric ulcers healed significantly more frequently in those patients who had discontinued NSAIDs (95\% vs. 63\%, $P=0.001$ ). Duodenal ulcers also healed in significantly more patients who discontinued NSAIDs ( $100 \%$ vs. $84 \%, P=0.006)$ [7].

PPIs have been shown more effective than H2RAs for healing ulcers in patients who continue NSAIDs. In a double-blind study of 541 patients with confirmed ulcers and continued NSAID use, patients were randomized to receive omeprazole $20 \mathrm{mg}$ or $40 \mathrm{mg}$ daily or ranitidine $150 \mathrm{mg}$ twice daily [8]. After 8 weeks, the healing rates for all types of endoscopic damage were higher in those treated with omeprazole as compared with ranitidine. The gastric-ulcer healing rates were significantly higher with $20 \mathrm{mg}$ omeprazole and $40 \mathrm{mg}$ omeprazole versus ranitidine ( $84 \%$ vs. $87 \%$ vs. $64 \%$, respectively; $P<0.001$ for both doses of omeprazole vs. ranitidine). The duodenal ulcer healing rates were significantly better with $20 \mathrm{mg}$ omeprazole versus ranitidine ( $92 \%$ vs. $81 \%$, respectively; $P=0.03)$, but for the comparison of $40 \mathrm{mg}$ omeprazole with ranitidine $(88 \%$ vs. $81 \%)$ the improvement failed to reach significance $(P=0.17)$. Another trial of similar design compared lansoprazole $15 \mathrm{mg}$ or $30 \mathrm{mg}$ once daily with ranitidine $150 \mathrm{mg}$ twice daily in the healing of NSAID-associated gastric ulcers among patients who continued taking their NSAIDs. Patients receiving $15 \mathrm{mg}$ and $30 \mathrm{mg}$ lansoprazole had significantly higher ulcer healing rates than patients on ranitidine $(73 \%$ vs. $75 \%$ vs. $57 \%$, respectively; $P<0.05$ for comparison of both doses of lansoprazole vs. ranitidine) [9].

PPIs also appear to be more effective than misoprostol at healing ulcers when patients continue NSAIDs. A trial compared misoprostol $200 \mu \mathrm{g}$ four times daily with omeprazole $20 \mathrm{mg}$ or $40 \mathrm{mg}$ once daily. After 8 weeks of treatment, healing of gastric ulcers occurred significantly more frequently among patients treated with $20 \mathrm{mg}$ omeprazole compared with those on misoprostol $(87 \%$ vs. $73 \%$, respectively; $P=0.004)$. The healing rate for omeprazole $40 \mathrm{mg}$ was better than that for misoprostol ( $80 \%$ vs. $73 \%$, respectively), although this difference did not attain statistical significance in the study $(P=0.14)$. The rates of healing of duodenal ulcers were also significantly higher in the groups given omeprazole $20 \mathrm{mg}$ or $40 \mathrm{mg}$ as compared with misoprostol (93\% vs. $89 \%$ vs. $77 \%$, respectively; $P<0.001$ for comparison of both doses of omeprazole vs. misoprostol) [10].

\section{Prevention of NSAID injury with proton pump inhibitors}

Given the encouraging data regarding the value of acid suppression with PPIs for NSAID ulcer healing, investigators next turned to the question of whether a PPI given along with an NSAID could prevent the well-characterized injury that can be quantitated by endoscopy. Many studies were performed whereby NSAID users without endoscopic injury at baseline were studied with and without concomitant PPI co-therapy, and have been summarized systematically.

The current Cochrane review (search date May 2009) [5] updated prior systematic reviews [11]. Six randomized controlled trials (RCTs) with 1,259 participants assessed the effect of PPIs on the prevention of NSAID-induced upper GI injury. PPIs significantly reduced the risk of both endoscopic duodenal ulcers $(\mathrm{RR}=0.20$; 95\% confidence interval $(\mathrm{CI})=0.10$ to 0.39 ) and gastric ulcers 
$(\mathrm{RR}=0.39 ; 95 \% \mathrm{CI}=0.31$ to 0.50$)$ compared with placebo. The results were similar for both primary and secondary prophylaxis trials. Dyspeptic symptoms were significantly reduced by PPIs in all four trials that used this as an endpoint [5].

Few comparative studies exist, but the evidence suggests that misoprostol and PPIs are superior to ranitidine and that, in two trials for secondary prophylaxis, PPIs are superior to misoprostol for prevention of duodenal ulcer $(\mathrm{RR}=0.29,95 \% \mathrm{CI}=0.15$ to 0.56$)$ but not gastric ulcer [5]. As discussed elsewhere in this supplement, endoscopy as a surrogate has been a controversial endpoint for clinical outcomes. However, such studies do provide insights that have proven relevant to clinical outcomes. An example is our study of esomeprazole $20 \mathrm{mg}$ and $40 \mathrm{mg}$ for treatment of NSAID-induced dyspepsia as well ulcer prevention among $H$. pylori-negative patients at increased risk of developing ulcers (age $>60$ or recent gastric or duodenal ulcer) [12]. In that study we demonstrated for the first time that PPIs provided ulcer risk reduction not only for nonselective NSAID exposure, but also for patients taking COX-2 selective agents as well.

In summary, PPIs are effective in reducing endoscopic ulceration and dyspepsia symptoms. There is good evidence that PPIs are more effective than standard doses of H2RAs, and that PPIs are as effective as, but better tolerated than, misoprostol in preventing ulcers. As noted by the recent Cochrane review, there are limited data - three RCTs with 298 participants - that did assess the efficacy of double-dose H2RAs for the prevention of NSAID-induced upper GI toxicity. Double-dose H2RAs, when compared with placebo, were associated with a statistically significant reduction in the risk of both duodenal ulcers $(\mathrm{RR}=0.26 ; 95 \% \mathrm{CI}=0.11$ to 0.65$)$ and gastric ulcers ( $R R=0.44 ; 95 \% \mathrm{CI}=0.26$ to 0.74 ). This $56 \%$ relative risk reduction in gastric ulcer corresponds to a $12 \%$ absolute risk difference (from $23.1 \%$ to $11.3 \%$ ) [5]. However, there are no direct comparisons of double-dose H2RAs with PPIs for NSAID risk reduction. While comparisons of risk reduction across trials of different patient populations are problematic, PPIs do appear to be more effective when comparing the endoscopic endpoint trials.

\section{Cycylooxygenase-2 NSAIDs versus conventional NSAIDs plus proton pump inhibitors}

Two RCTs have addressed this question and support the similarity of each of these risk-reducing approaches. In the first trial, among $287 \mathrm{H}$. pylori-negative patients whose bleeding peptic ulcers had healed, recurrent bleeding over 6 months of observation occurred in $4.9 \%$ (95\% CI $=3.1$ to 6.7 ) of those randomized to celecoxib $200 \mathrm{mg}$ twice daily plus placebo, and occurred in $6.4 \%$ (95\% CI $=4.3$ to 8.4 ) for diclofenac $75 \mathrm{mg}$ daily plus omeprazole $20 \mathrm{mg}$ daily $(P=\mathrm{NS})$ [13]. In the second trial, with a similar population over the same period, recurrent ulcer complications occurred in $3.7 \%$ (95\% CI $=0.0$ to 7.3) of those given celecoxib $200 \mathrm{mg}$ daily, compared with $6.3 \%(95 \% \mathrm{CI}=1.6$ to 11.1$)$ of those given naproxen $750 \mathrm{mg}$ daily plus lansoprazole $30 \mathrm{mg}$ daily (celecoxib statistically noninferior to lansoprazole co-therapy) [14].

A number of observational studies have provided support for the value of PPI gastroprotection as an alternative approach to the use of a COX-2 specific inhibitor. In a multicenter study of hospitalized patients in Spain, PPI co-therapy was associated with a marked relative risk reduction $(\mathrm{RR}=0.33,95 \% \mathrm{CI}=0.27$ to 0.39$)$ in ulcer bleeding [15]. In a large Tennessee Medicaid database, investigators found similar results. Concurrent users of NSAIDs and PPIs had a 54\% (27 to 72\%) risk reduction, very similar to the $50 \%$ (27 to $66 \%$ ) reduction for concurrent users of PPIs and COX-2 selective inhibitors [16].

COX-2 selective inhibitors alone may not provide sufficient ulcer risk reduction for very high GI risk patients. This was recently established by Chan and colleagues, who studied individuals at highest risk of a GI complication: those with previous GI bleeding. They reported that the twice-daily addition of a PPI to twicedaily celecoxib lowered the 13-month recurrence of ulcer bleeding to $0 \%$ in the combined treatment group compared with $8.9 \%$ for celecoxib alone $(95 \%$ CI for the difference $=4.1$ to 13.7 ) [17].

While a number of studies have provided observational data to support these small RCTs, a recent case-control study from Canada has provided compelling real-world evidence. Targownik and colleagues observed that any of the gastroprotective strategies - nonselective NSAID + PPI, nonselective NSAID + misoprostol, COX-2 selective NSAID alone and COX-2 selective NSAID + PPI - were all associated with a significantly reduced risk of developing an upper GI complication [18]. COX-2 selective agents were no more likely to reduce risk than PPI cotherapy, and the combination of a COX-2 selective NSAID with a PPI was associated with the greatest risk reduction.

In summary, the risks of further ulcer complications with conventional NSAIDs plus PPI co-therapy and COX-2 NSAIDs are comparable for high-risk patients. The combination of COX-2 NSAID and PPI co-therapy can further reduce this risk.

\section{Helicobacter pylori eradication}

Much debate has centered on the impact of H. pylori regarding ulcer risk in NSAID users, and the weight of the evidence supports the conclusion that it is an independent ulcer risk factor [19]. In a comparative study of H. pylori eradication and PPI co-therapy for patients with 
a recent history of upper GI bleeding healed by PPI, both treatments were equally effective in preventing rebleeding among patients taking low-dose aspirin, but PPI was superior to H. pylori eradication for those taking NSAIDs [20].

In summary, while there is limited evidence that $H$. pylori eradication alone may reduce ulceration in NSAID users, and while the European Helicobacter Pylori Group has recommended that H. pylori eradication be at least considered in patients in whom long-term NSAID treatment is contemplated [21], this recommendation has not been enthusiastically taken up in practice. H. pylori infection remains a risk factor for ulcer complications, and H. pylori eradication should be employed as an additional precaution for patients using NSAIDs with a history of ulcer disease.

\section{Practical considerations}

While the underutilization of gastroprotective strategies for patients at risk for NSAID complications is well recognized as a failure of physician behavior, patient adherence to medication is an equally important barrier to the success of any risk-reducing strategy. Since a less toxic NSAID provides so-called intrinsic protection, cotherapy requires the additional PPI tablet to be taken along with the anti-inflammatory medication. Several database studies have suggested that $80 \%$ adherence to co-prescribed PPIs is required for the ulcer risk reduction benefit to occur [22]. Studies document that nonadherence was associated with a fourfold increased risk of upper GI complications in high-risk patients, with the risk increasing by $16 \%$ for every $10 \%$ reduction in nonaderence [23]. The fixed-dose combination of a PPI with naproxen, recently introduced, represents one approach to this problem.

Current treatment guidelines state that NSAIDs should be used at the lowest effective dose and that their longterm use should be avoided if possible [24-29]. For patients at GI risk, guidelines from the American College of Gastroenterology, the European League Against Rheumatism, and the First International Working Party on Gastrointestinal and Cardiovascular Effects of NSAIDs and Anti-Platelet Drugs recommend the use of a nonselective NSAID plus a gastroprotective agent (PPI or misoprostol) or a COX-2 selective inhibitor. The American College of Gastroenterology and the First International Working Party on Gastrointestinal and Cardiovascular Effects of NSAIDs and Anti-Platelet Drugs recommend that a PPI or misoprostol be used with a COX-2 inhibitor in those patients at high risk of GI events, and the recent National Institute for Health and Clinical Excellence guidelines recommend that a PPI should be used with all NSAIDs, including COX-2 inhibitors [29]. The 2008 American College of Cardiology
Foundation/American College of Gastroenterology/ American Heart Association expert consensus document on reducing the risks of antiplatelet therapy and NSAID use states that PPIs are the preferred gastroprotective agent for the treatment and prevention of GI toxicity associated with NSAIDs and aspirin [25].

For patients with a prior GI event and a high cardiovascular risk, several guidelines recommend that nonselective NSAIDs and COX-2 inhibitors are not appropriate and that other forms of treatment need to be considered. The guidelines from the First International Working Party on Gastrointestinal and Cardiovascular Effects of NSAIDs and Anti-Platelet Drugs, however, also propose that naproxen with a PPI or misoprostol may be considered for some of these patients, targeting those whose cardiovascular risk outweighs their GI risk.

To synthesize current treatment approaches, we have developed a $2 \times 2$ table (Table 1) to guide appropriate selection of an NSAID driven by assessment of an individual's cardiovascular and GI risk [30,31]. The following illustrates how this can guide NSAID selection based on GI and cardiovascular risk factors, together with assessments for efficacy and/or drug intolerance. Inherent to the table is the appropriate use of aspirin clearly of benefit for secondary prevention of cardiovascular events. For primary prevention, we advocate the use of a risk calculation and restriction of aspirin to those who meet 10-year risk high enough to justify therapy, based on national guidelines.

\section{Patients with no cardiovascular risk (not receiving aspirin) and low gastrointestinal risk}

A reasonable option for initial therapy would be a nonselective NSAID. The use of a more expensive but safer COX-2 inhibitor is not advocated due only to the issue of increased cost.

\section{Patients with no cardiovascular risk (not receiving aspirin)} and with moderate to high gastrointestinal risk

For patients with moderate GI risk, therapy might begin with a COX-2 selective NSAID, where the evidence for its benefit is strongest. The combination of a nonselective NSAID with a PPI appears to provide similar GI benefits. For patients with a history of GI bleeding, the addition of a PPI is an evidence-based recommendation.

\section{Patients with no gastrointestinal risk and with cardiovascular risk (receiving aspirin)}

For patients with cardiovascular risk but low GI risk, naproxen may offer advantages not present in other NSAIDs. If the patient is intolerant or finds naproxen ineffective, selection of an NSAID that does not interact with aspirin is essential. Ibuprofen is thus contraindicated. Choices include low-dose celecoxib, which has 
Table 1. Clinicians' guide to anti-inflammatory therapy

\begin{tabular}{lll}
\hline Cardiovascular risk & No or low gastrointestinal risk & Increased gastrointestinal risk \\
\hline No cardiovascular risk (no aspirin use) & Nonselective NSAID (cost consideration) & COX-2 selective inhibitor or nonselective NSAID + PPI \\
& & COX-2 selective inhibitor + PPI for those with prior \\
gastrointestinal bleeding \\
Cardiovascular risk (aspirin use) & Naproxen ${ }^{\text {a }}$ & PPI irrespective of NSAID \\
& Addition of PPI because gastrointestinal risk of & Naproxen if cardiovascular risk outweighs \\
& aspirin + NSAID combination typically warrants & gastrointestinal risk \\
& gastroprotection & COX-2 selective inhibitor + PPI for those with \\
& previous gastrointestinal bleeding
\end{tabular}

PPI, proton pump inhibitor. Modified from [30]. a Nonselective NSAID without established aspirin interaction or (low-dose) cyclooxygenase (COX)-2 selective NSAID if naproxen is ineffective.

not been implicated as carrying cardiovascular concerns at high or multiple daily doses. Diclofenac may also be considered. Concomitant treatment with a PPI, as appropriate, should be strongly considered in patients taking any NSAID and aspirin, since the risk of ulcer bleeding in patients taking multiple agents is increased.

\section{The patient with both increased gastrointestinal and cardiovascular risks (on aspirin)}

Low-dose celecoxib together with a PPI should be used for patients who have both GI and cardiovascular risks but in whom the GI risk, such as a recent ulcer bleed, is of greater relevance. If the cardiovascular risk is of greater concern, naproxen + PPI is favored [31].

\section{Key messages}

- PPIs provide potent and long-lasting inhibition of gastric acid secretion.

- PPIs can heal NSAID-associated ulcers, even if NSAIDs are continued.

- PPIs reduce the risk of ulcerations due to NSAIDs in RCTs where endoscopic ulcers are used as the primary endpoint.

- Large RCT outcome trials of PPI co-therapy have not been performed.

- RCTs in high-risk patients demonstrate that PPI + nonselective NSAID provides similar rates of symptomatic ulcer recurrence rates as a COX-2 selective inhibitor.

- Since COX-2 selective agents have demonstrated superiority of nonselective NSAIDS in GI outcome studies, the two strategies are considered therapeutically equivalent.

- There is an additive benefit of PPI co-therapy to use of a COX-2 selective agent to further reduce GI risk.

- NSAID medication selection should consider both the individual patient's $\mathrm{GI}$ and $\mathrm{CV}$ risk profile.

\section{Abbreviations}

COX, cyclooxygenase; $\mathrm{Gl}$, gastrointestinal; $\mathrm{H}_{2} \mathrm{RA}, \mathrm{H}_{2}$-receptor antagonist; NSAID, nonsteroidal anti-inflammatory drug; PPI, proton pump inhibitor; RCT, randomized controlled trial; RR, relative risk.

\section{Competing interests}

JMS has in the past 5 years been a consultant for Astra-Zeneca, Pozen, Pfizer, Novartis, Horizon, TAP, Johnson and Johnson, Nicox, and Merck.

\section{Declaration}

This article has been published as part of Arthritis Research \& Therapy Volume 15 Suppl 3, 2013:'Gastroprotective NSAIDS'. The full contents of the supplement are available online at http://arthritis-research.com/ supplements/15/S3. The supplement was proposed by the journal and developed by the journal in collaboration with the Guest Editor. The Guest Editor assisted the journal in preparing the outline of the project but did not have oversight of the peer review process. The Guest Editor serves as a clinical and regulatory consultant in drug development and has served as such consultant for companies which manufacture and market NSAIDs including Pfizer, Pozen, Horizon Pharma, Logical Therapeutics, Nuvo Research, Iroko, Imprimis, JRX Pharma, Nuvon, Medarx, Asahi. The articles have been through the journal's standard peer review process. Publication of this supplement has been supported by Horizon Pharma Inc. Duexis (ibuprofen and famotidine) is a product marketed by the sponsor.

Published: 24 July 2013

\section{References}

1. Walt R, Katschinski B, Logan R, Ashley J, Langman M: Rising frequency of ulcer perforation in elderly people in the United Kingdom. Lancet 1986, 1:489-492.

2. Jones R, Rubin G, Berenbaum F, Scheiman J: Protection of the upper gastrointestinal tract in patients taking nonsteroidal anti-inflammatory drugs. Am J Med 2008, 121:464-474.

3. Dieppe PA, Ebrahim S, Martin RM, Juni P: Lessons from the withdrawal of rofecoxib. BMJ 2004, 329:867-868

4. Scheiman JM: NSAIDs, cytoprotection, and gastrointestinal injury. Gastroenterol Clin North Am 1996, 25:279-298.

5. Rostom A, Dube C, Wells GA, Tugwell P, Welch V, Jolicoeur E, McGowan J, Lanas A: Prevention of NSAID-induced gastroduodenal ulcers. Cochrane Database Syst Rev 2002, 4:CD002296.

6. Lazzaroni M, Porro GB: Management of NSAID-induced gastrointestinal toxicity: focus on proton pump inhibitors. Drugs 2009, 69:51-69.

7. Lancaster Smith MJ, Jadeberg ME, Jackson DA: Ranitidine in the treatment of non steroidal antiinflammtory drug associated gastric and duodenal ulcer. Gut 1991, 32:252-255.

8. Walan A, Bader JP, Classen M, Lamers CB, Piper DW, Rutgersson K, Eriksson S: Effect of omeprazole and ranitidine on ulcer healing and relaspe rates in patients with benign gastric ulcer. NEngl J Med 1989, 320:69-75.

9. Agrawal NM, Campbell DR, Safdi MA, Lukasik NL, Huang B, Haber MM: Superiority of lansoprazole vs ranitidine in healing nonsteroidal antiinflammtory drug-associated gastric ulcers: results of a double-blind, randomized, multicenter study. NSAID-Associated Gastric Ulcer Study Group. Arch Intern Med 2000, 160:1455-1461.

10. Hawkey CJ, Karrasch JA, Szczepanski L, Walker DG, Barkun A, Swannell AJ, Yeomans ND: Omeprazole compared with misoprostol for ulcers associated with nonsteroidal antiinflammatory drugs: Omeprazole versus Misoprostol for NSAID-induced Ulcer Management (OMNIUM) Study 
Group. N Engl J Med 1998, 338:727-734.

11. Hooper L, Brown TJ, Elliott R, Payne K, Roberts C, Symmons D: The effectiveness of five strategies for the prevention of gastrointestinal toxicity induced by nonsteroidal anti-inflammatory drugs: a systematic review. BMJ 2004, 329:948.

12. Scheiman JM, Yeomans ND, Talley NJ, Vakil N, Chan FK, Tulassay Z, Rainoldi IL, Szczepanski L, Ung KA, Kleczkowski D, Ahlbom H, Naesdal J, Hawkey C: Prevention of ulcers by esomeprazole in at-risk patients using nonselective NSAIDs and COX 2 inhibitors. Am J Gastroenterol 2006 101:701-710.

13. Chan FK, Hung LC, Suen BY, Wu JC, Lee KC, Leung VK, Hui AJ, To KF, Leung WK, Chung SC, Sung JJ: Celecoxib versus diclofenac and omeprazole in reducing the risk of recurrent ulcer bleeding in patients with arthritis. N Eng/ J Med 2002, 347:2104-2110

14. Lai KC, Chu KM, Hui WM, Wong BCY, Hu HC, Wong WM, Chan AOO, Wong J, Lam SK: Celecoxib compared to lansoprazole and naproxen to prevent gastrointestinal ulcer complications. Am J Med 2005, 118:1271-1278.

15. Lanas A, García-Rodríguez LA, Arroyo MT, Bujanda L, Gomollón F, Forné M, Aleman S, Nicolas D, Feu F, González-Pérez A, Borda A, Castro M, Poveda MJ, Arenas J; Investigators of the Asociación Española de Gastroenterología: Effect of antisecretory drugs and nitrates on the risk of ulcer bleeding associated with nonsteroidal anti-inflammatory drugs, antiplatelet agents, and anticoagulants. Am J Gastroenterol 2007, 102:507-515.

16. Ray WA, Chung CP, Stein CM, Smalley WE, Hall K, Arbogast PG, Griffin MR: Risk of peptic ulcer hospitalizations in users of NSAIDS within gastroprotective cotherapy versus coxibs. Gastroenterology 2007, 133:790-798.

17. Chan FKL, Wong VWS, Suen BY, Wu JC, Ching JY, Hung LC, Hui AJ, Leung VK, Lee VW, Lai LH, Wong GL, Chow DK, To KF, Leung WK, Chiu PW, Lee YT, Lau JY, Chan HL, Ng EK, Sung JJ: Combination of a cyclooxygenase-2 inhibitor and a proton pump inhibitor for the prevention of recurrent ulcer bleeding in patients with very high gastrointestinal risk: a double-blind, randomized trial. Lancet 2007, 369:1621-1626.

18. Targownik, LE, Metge CJ, Leung S, Chateau DG: The relative efficiacies of gastroprotective strategies in chronic users of nonsteroidal antiinflammatory drugs. Gastroenterology 2008, 134:937-944

19. Huang J-Q, Sridhar S, Hunt RH: Role of Helicobacter pylori infection and non-steroidal anti-inflammatory drugs in peptic-ulcer disease: a metaanalysis. Lancet 2002, 359:14-22.

20. Chan FK, Chung SC, Suen BY, Lee YT, Leung WK, Leung VK, Wu JC, Lau JY, Hu $Y$, Lai MS, Chan HL, Sung JJ: Preventing recurrent upper gastrointestinal bleeding in patients with Helicobacter pylori infection who are taking low-dose aspiring or naproxen. N Engl J Med 2001, 344:967-973.

21. Malfertheiner $P$, Megraud F, O'Morain C, Hungin AP, Jones R, Axon A, Graham DY, Tytgat G; European Helicobacter Pylori Study Group: Current concepts in the management of Helicobacter pylori infection - the Maastricht 2-2000 Consensus Report. Aliment Pharmacol Ther 2002, 16:167-180.

22. Goldstein JL, Howard KB, Walton SM, McLaughlin TP, Kruzikas DT: Impact of adherence to concomitant gastroprotective therapy on nonsteroidalrelated gastroduodenal ulcer complications. Clin Gastroenterol Hepatol 2006, 4:1337-1345
23. Van Soest EM, Sturkenboom MC, Dieleman JP, Verhamme KM, Siersema PD Kuipers EJ: Adherence to gastroprotection and the risk of NSAID-related upper gastrointestinal ulcers and haemorrhage. Aliment Pharmacol Ther 2007, 26:265-275.

24. Lanza FL, Chan FK, Quigley EM: Guidelines for prevention of NSAID-related ulcer complications. Am J Gastroenterol 2009, 104:728-738.

25. Chan FK, Abraham NS, Scheiman JM, Laine L: Management of patients on nonsteroidal anti-inflammatory drugs: a clinical practice recommendation from the First International Working Party on Gastrointestinal and Cardiovascular Effects of Nonsteroidal Anti-inflammatory Drugs and Antiplatelet Agents. Am J Gastroenterol 2008, 103:2908-2918.

26. Zhang W, Doherty M, Arden N, Bannwarth B, Bij|sma J, Gunther KP, Hauselmann HJ, Herrero-Beaumont G, Jordan K, Kaklamanis P, Leeb B, Lequesne M, Lohmander S, Mazieres B, Martin-Mola E, Pavelka K, Pendleton A, Punzi L, Swoboda B, Varatojo R, Verbruggen G, Zimmermann-Gorska I, Dougados M; EULAR Standing Committee for International Clinical Studies Including Therapeutics: EULAR evidence based recommendations for the management of hip osteoarthritis: report of a task force of the EULAR Standing Committee for International Clinical Studies Including Therapeutics (ESCISIT). Ann Rheum Dis 2005, 64:669-681.

27. Zhang W, Moskowitz RW, Nuki G, Abramson S, Altman RD, Arden N, BiermaZeinstra S, Brandt KD, Croft P, Doherty M, Dougados M, Hochberg M, Hunter DJ, Kwoh K, Lohmander LS, Tugwell P: OARSI recommendations for the management of hip and knee osteoarthritis, Part II: OARSI evidencebased, expert consensus guidelines. Osteoarthritis Cartilage 2008, 16:137-162.

28. Bhatt DL, Scheiman J, Abraham NS, Antman EM, Chan FK, Furberg CD, Johnson DA, Mahaffey KW, Quigley EM, Harrington RA, Bates ER, Bridges CR, Eisenberg MJ, Ferrari VA, Hlatky MA, Kaul S, Lindner JR, Moliterno DJ, Mukherjee D, Schofield RS, Rosenson RS, Stein JH, Weitz HH, Wesley DJ; American College of Cardiology Foundation Task Force on Clinical Expert Consensus Documents: ACCF/ACG/AHA 2008 expert consensus document on reducing the gastrointestinal risks of antiplatelet therapy and NSAID use: a report of the American College of Cardiology Foundation Task Force on Clinical Expert Consensus Documents. J Am Coll Cardio/ 2008 52:1502-1517.

29. Osteoarthritis. The Care and Management of Osteoarthritis in Adults [http://www.nice.org.uk/nicemedia/pdf/CG59NICEguideline.pdf]

30. Scheiman JM, Fendrick AM: Summing the risk of NSAID therapy. Lancet 2007, 369:1580-1581

31. Scheiman JM: Balancing risks and benefits of cyclooxygenase-2 selective NSAIDs. Gastroenterol Clin North Am 2009, 38:305-314.

doi:10.1186/ar4177

Cite this article as: Scheiman JM: The use of proton pump inhibitors in treating and preventing NSAID-induced mucosal damage. Arthritis Research \& Therapy 2013, 15(Suppl 3):S5. 